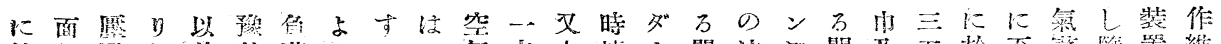

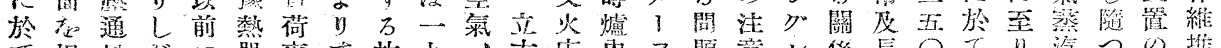

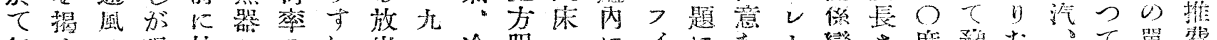

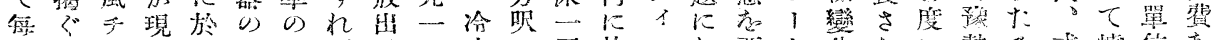

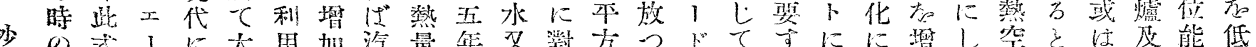

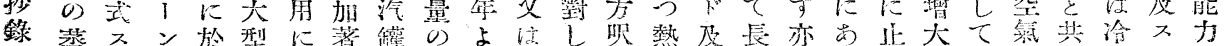

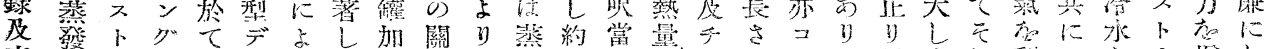

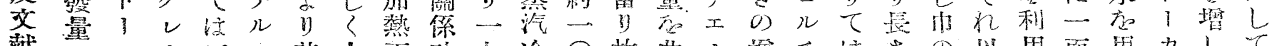

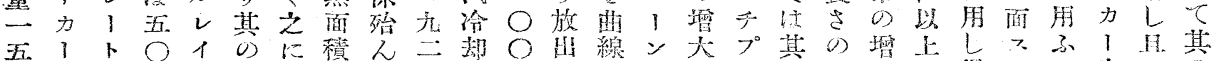

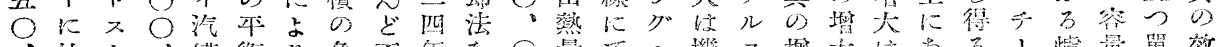

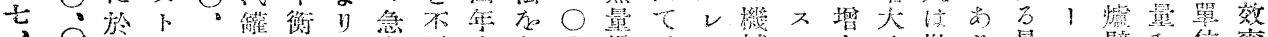

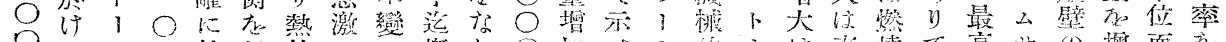

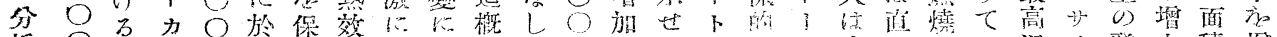

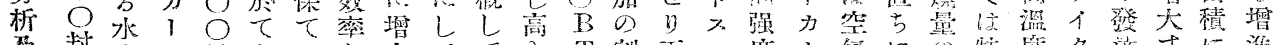

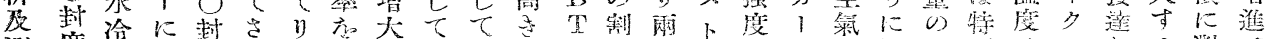

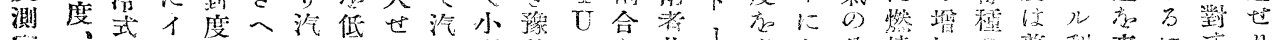

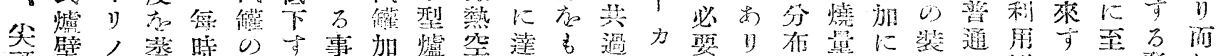

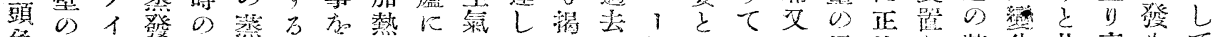

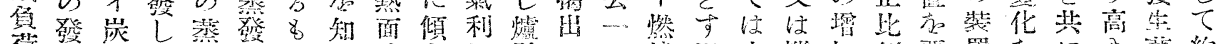

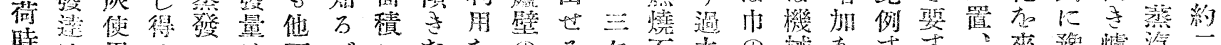

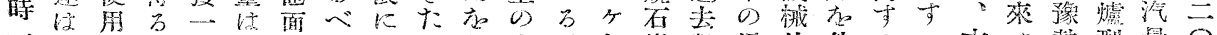

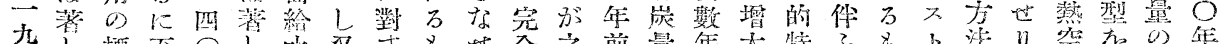

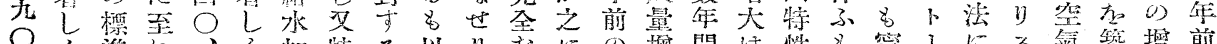

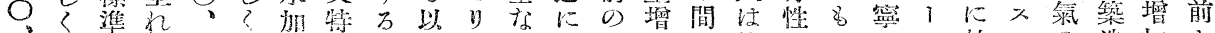

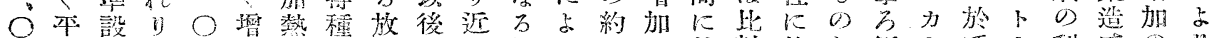

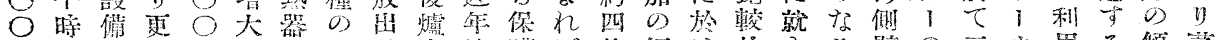

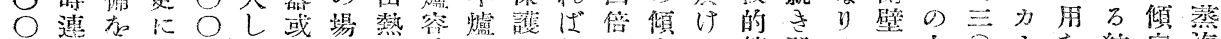

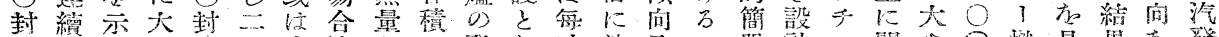

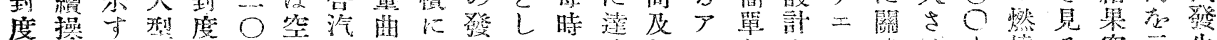

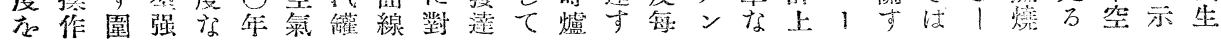

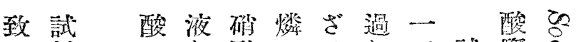

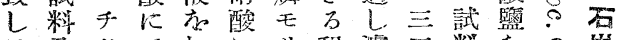

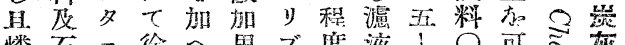
燐石二徐乞画ブ度液「○可ミ存

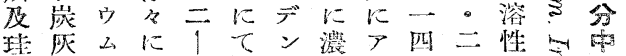

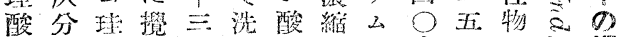

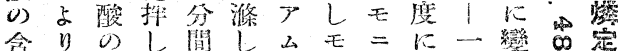

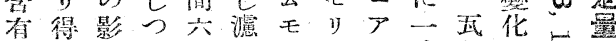

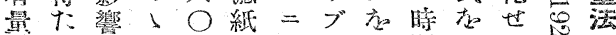

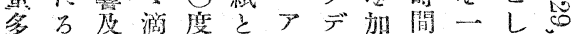

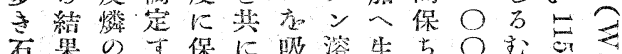

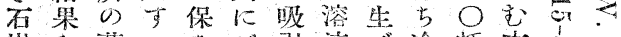

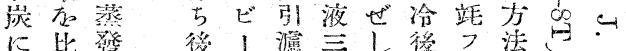

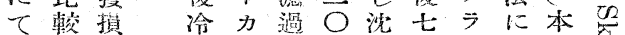

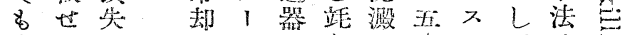

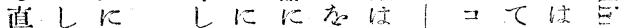
接に就過移て加濃八に摈灭的

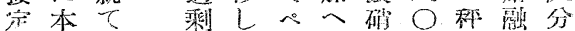

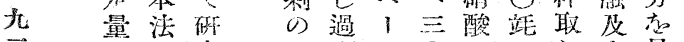

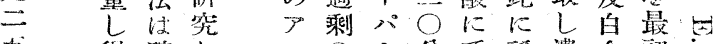
得磪しルの1分て稀濃全初

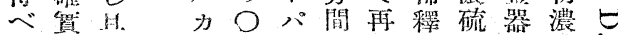
专に各り・儿四溶し酸具硫 利し種占一プ○解一三使酸恕 (む)

り 結 法 果

西 之
○規店度し五、用飞导 - 定时に結分六のて苞

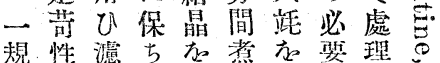
定 雷 瀜冷生沸加車L

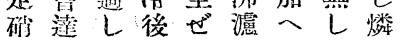

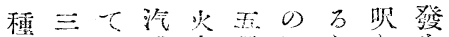

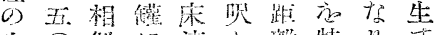
改 ○储に速之溜特り方

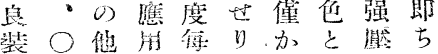

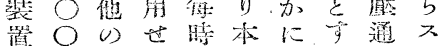

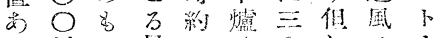

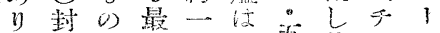

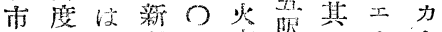

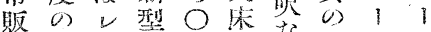

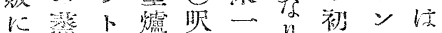

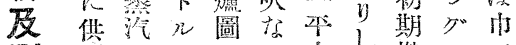

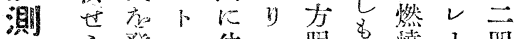

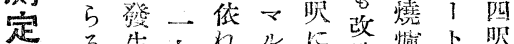

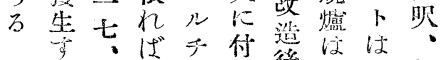
亦狗紷プ每後前無長 亦狗宸儿時殆了煙さ 卜數機レ七点 1 粉三

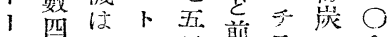
力杂レル封前及に蓑。 1 石山儿給感テアひ吹

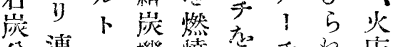
分連一機燒圭テれ床

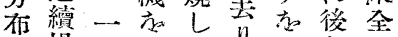

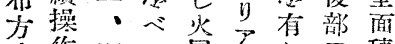
法作犲ン㲊〉しア積

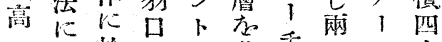

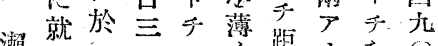

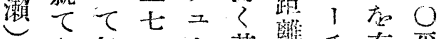

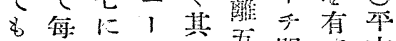
各時しブ严琶間方方 
ろ虨位 の之 8摖在試强在 のに示驗度見 と侬しに順 万 云り然當位に ひ破しり医问 得碎てて 正 轉

べす兩秎磪試

しる者末に驗

よの生はの

り值成一方

も の 基致 遥

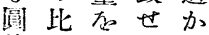

简は比ざに

内略齵万粉

に一世名碎

於定し大作

てなに唶用

阥り本に强

落敌琵は L

のにに二又

現问見致兩

象轉万す指

行試如

注驗了

れに兩

衙當試

新繁 り 驗

新にてを

村依交占

碎孷 L”

くは順

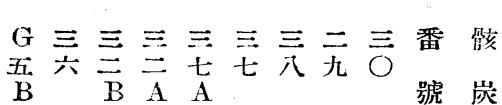

五五五六七七七八分䠯包

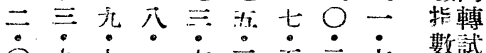

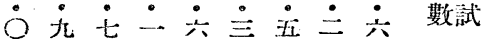

四六六七七八七七七驗裂 七六三七厹少六指落

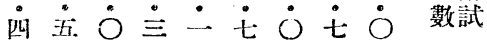

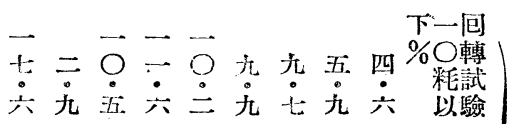

粉

衯

に;

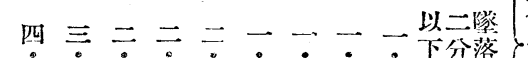

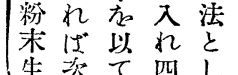

後て 分究的

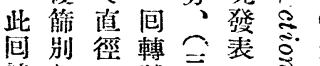

轉 $L$ 一試三に

陚米驗英 $し \leftrightharpoons$ 回

驗徑、と國

指四長は能乞

數 $\bigcirc \div$ 今宸

老粍米旦製鹃

從のの獨呰篮可故献

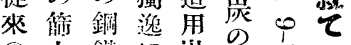

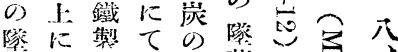

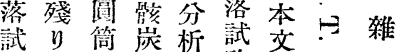

驗たに硬に驗は式 指 万試さ就と英 數量料 0 回國就 との五標報 轉 北 比百 $\bigcirc$ 準告陚部

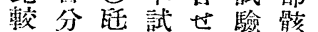
小紷方驗り れ者入法栄研

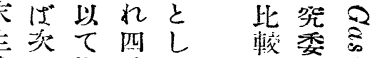

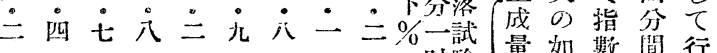
量如數間行 于 $\mathrm{O}$ \& 回の 轉 に v) $L$

\section{抄 交} 公 (1) (1)

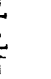

公會 空 能行要

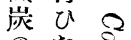
のたた 塚方沓

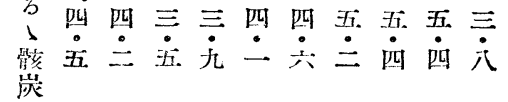

比嵱卜|ン黄の監分差必之ドカッキてを

\begin{tabular}{|c|c|c|c|}
\hline $\begin{array}{l}\text { Kカ } \\
\text { 加 }\end{array}$ & $\begin{array}{l}\text { 万力 } \\
\text { 力゙ }\end{array}$ & 分 & 燃 \\
\hline $\begin{array}{l}\text { 熱ボ } \\
L=\end{array}$ & ソボ & 留 & \\
\hline 添儿 & ע & & \\
\hline 加 = & $=$ & ガ & \\
\hline $\begin{array}{l}\text { せサツ } \\
\text { 万ケ }\end{array}$ & " & & \\
\hline $\begin{array}{l}\text { ろ } \\
\text { ガル }\end{array}$ & $\begin{array}{l}\text { ケ } \\
\text { ル }\end{array}$ & y & \\
\hline ソ衣 & 存 & & \\
\hline リ六 & 添 & 1) & 料 \\
\hline & 加 & & \\
\hline & せ & & \\
\hline
\end{tabular}

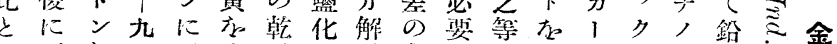
热ボソボ

$L=\eta=$ 的

添ルンル

扣 = =

ろケケ、

ガル ル

六添

度せン

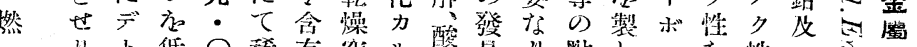

り卜低 $\bigcirc$ 稀有空儿酰胃り點 $し=$ 占性 $=$

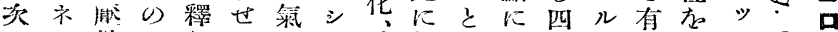

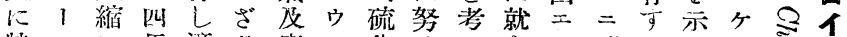

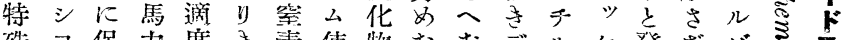

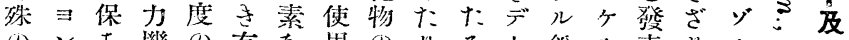

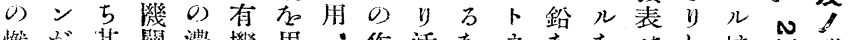

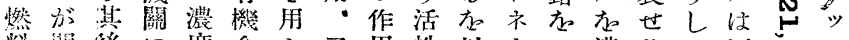

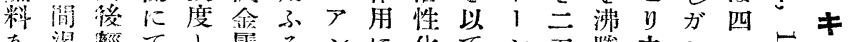

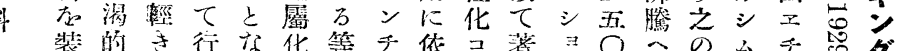

入に, ひし合け, り口者ン度ク際スルい坜

試起ツた使物困ッ活イ等の至サ注及鉛岕制

四四四厴最驗乃キり角の難ク性ドは機 ○ン意マ及

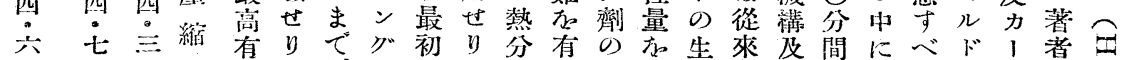

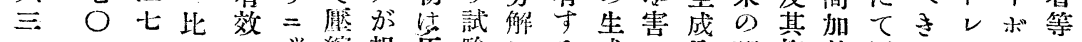

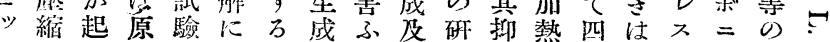

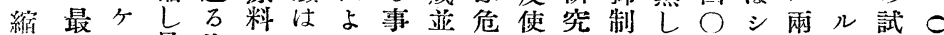

此高ル最渠が竪りなと險角成の鉛分么氏二驗氞

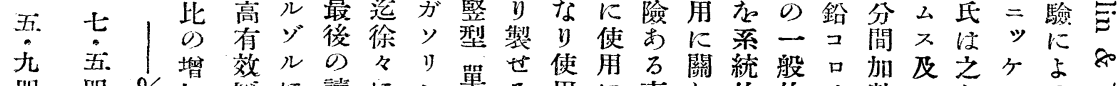

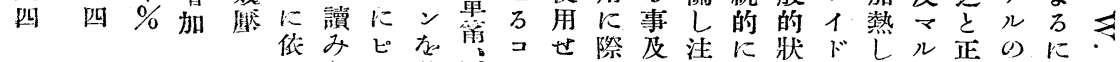

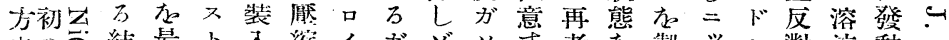

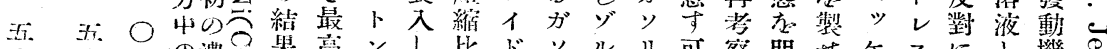

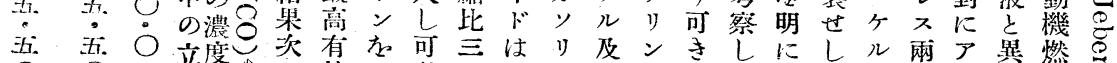

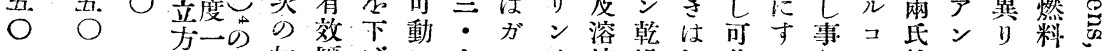

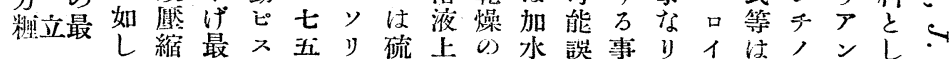

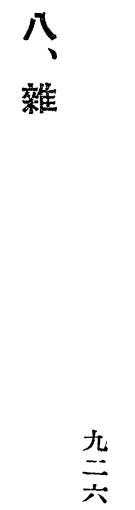

